\title{
Phylogeny of the industrial relevant, thermophilic genera Myceliophthora and Corynascus
}

\author{
Joost van den Brink • Robert A. Samson • \\ Ferry Hagen • Teun Boekhout • Ronald P. de Vries
}

Received: 17 January 2011 / Accepted: 16 May 2011 / Published online: 28 May 2011

(C) The Author(s) 2011. This article is published with open access at Springerlink.com

\begin{abstract}
Species of the genus Myceliophthora and its teleomorph Corynascus have attracted increasing interest due to their potential to produce thermostable enzymes. This study re-assessed the phylogenetic relationship of 49 isolates of nine species belonging to Myceliophthora and Corynascus. One species, M. vellerea, was shown not to belong to the genus Myceliophthora and should be placed in the genus Ctenomyces. The other species belonged to two phylogenetic clusters: mesophilic fungi with the type species $M$. lutea and $C$. sepedonium, and thermophilic fungi with M. thermophila, M. hinnulea and C. thermophilus. The phylogenetic data provides no clear separation of the two genera Corynascus and Myceliophthora. To avoid confusion in future taxonomic studies, it is proposed that all existing Corynascus species be renamed to Myceliophthora, which is the old name and the one more frequently used. Furthermore, this study identified two groups within the isolates listed as M. thermophila and assigned one group (five isolates) to $M$. heterothallica based on AFLP analysis and mating behavior. This study provides new insights into the genetic differences within the genus Myceliophthora and will therefore be essential for the interpretation of future genomic and physiological studies of these species.
\end{abstract}

Keywords Myceliophthora $\cdot$ Corynascus $\cdot$ Thermophiles . M. heterothallica $\cdot$ M. thermophila . Thermophilic fungi . Multigene phylogeny $\cdot$ AFLP analysis $\cdot$ Mating behavior

Electronic supplementary material The online version of this article (doi:10.1007/s13225-011-0107-z) contains supplementary material, which is available to authorized users.

J. van den Brink · R. A. Samson · F. Hagen · T. Boekhout •

R. P. de Vries $(\bowtie)$

CBS-KNAW Fungal Biodiversity Centre,

P.O. Box 85167, 3508 AD Utrecht, The Netherlands

e-mail: r.devries@cbs.knaw.nl

\section{Introduction}

Species of genus Myceliophthora and its teleomorph Corynascus have attracted increasing interest due to their potential to produce thermostable enzymes. For instance, laccases of M. thermophila (basionym: Sporotrichum thermophilum) were shown to be thermostable with high activity after expression in different expression hosts (Berka et al. 1997; Bulter et al. 2003; Babot et al. 2011). Due to the potential of Myceliophthora to degrade lignocellulolytic plant material, many (hemi-)cellulolytic enzymes of $M$. thermophila are characterized and patented (Bhat and Maheshwari 1987; Roy et al. 1990; Sadhukhan et al. 1992; Badhan et al. 2007; Beeson et al. 2011). The importance of this fungal group has recently been underlined by the sequencing of the genome of M. thermophila isolate ATCC42464 (genome.jgi-psf.org/Spoth1).

The first Myceliophthora species, M. lutea, was described by Constantin and Matruchot in 1894 as a pathogen causing the 'vert de gris' mat disease of cultured mushrooms (Costantin 1892). This species was classified before as a member of the genus Chrysosporium (Carmichael 1962), but there after von Arx re-introduced the genus Myceliophthora and its type species M. lutea (von Arx 1973). Initially, three species were assigned to this genus: M. fergusii, M. lutea, and M. thermophila (van Oorschot 1980). Another species, M. vellerea, was most likely wrongly described as a Myceliophthora species based on morphological differences (Sigler et al. 1998). A fourth species, M. hinnulea, was assigned to the genus Myceliophthora by Awao and Udagawa (1983). The type species of the ascomycete genus Corynascus, C. sepedonium, was described by Emmons (1932). This species was originally part of the genus Thielavia before von Arx introduced the genus Corynascus. This genus can be distinguished from Thielavia by the presence of ascospores with two germ pores, one at 
each end (von Arx 1973). At that time, the genus Corynascus contained the species $C$. sepedonium and $C$. novoguineensis (von Arx 1973). Currently, seven Corynascus species are described: C. heterothallicus, C. novoguineensis, C. sepedonium, $C$. sexualis, $C$. similis, $C$. thermophilus and $C$. verrucosus (von Klopotek 1974; Stchigel et al. 2000).

Of all the species of these two genera, $M$. thermophila is most commonly used for applied research (Roy et al. 1990; Berka et al. 1997; Rosgaard et al. 2006; Badhan et al. 2007; Beeson et al. 2011). Several isolates of $M$. thermophila can grow at temperatures up to $50^{\circ} \mathrm{C}$ on cellulose-rich material and can decompose complex substrates such as birch chips, wood pulp and wheat straw (Bhat and Maheshwari 1987). M. thermophila was initially classified in the genus Sporotrichum (Fergus and Sinden 1969) before it was assigned to the genus Chrysosporium as C. thermophilum in 1974 (von Klopotek). Two years later Klopotek described Thielavia heterothallica as the teleomorph of C. thermophilum (von Klopotek 1976). The current names of these teleomorphs and anamorphs are Corynascus heterothallica and Myceliophthora thermophila, respectively (van Oorschot 1977; von Arx et al. 1984). A similar re-designation occurred for $C$. thermophilus and $M$. fergusii (Sigler et al. 1998). While the other species of Myceliophthora and Corynascus were not matched for their teleomorphic or anamorphic counterparts.

Although species within Myceliophthora and Corynascus are morphologically well described, a study comprising their genetic differences has not yet been performed. Understanding the genetic diversity of these genera is essential for upcoming genomic and applied studies based on the availability of the $M$. thermophila genome sequence. Our study describes the phylogenetic relationships of 49 isolates belonging to the genera Myceliophthora and Corynascus and investigates in detail the genetic diversity of $11 \mathrm{M}$. thermophila isolates.

\section{Materials and methods}

Strains

All strains used in this study are listed in Table 1, and are available from the CBS-KNAW Fungal Biodiversity Centre, Utrecht, the Netherlands (www.cbs.knaw.nl).

DNA extraction, sequencing analysis, and AFLP

Fungal genomic DNA was isolated using the FastDNA ${ }^{\circledR}$ Kit (Bio 101, Carlsbad, USA) according to the manufacturer's instructions. Amplification and sequencing of the ITS region (including internal transcribed spacer regions 1 and 2, and the 5.8S rRNA regions of the nuclear ribosomal RNA gene cluster), and parts of the elongation factor EFIA and the subunit of RNA polymerase II $R P B 2$ genes were performed as described by Houbraken et al. (2007). Fragments containing the ITS region were amplified using primers V9G (TTACGTCCCTGCCCTTTGTA) and RLR3R (GGTCCGTGTTTCAAGAC). Fragments containing the EFIA region were amplified using forward primer GCCCCCGGCCATCGTGACTTCAT and reverse primer ATGACACCGACAGCGACGGTCTG. Fragments containing the $R P B 2$ region were amplified using forward primer GACGACCGTGATCACTTTGG and reverse primer CCCATGGCCTGTTTGCCCAT. Contigs were assembled from the forward and reverse sequences using SeqMan from the Lasergene package (DNASTAR Inc., Madison, WI). The alignments of the sequence datasets using Clustal $\mathrm{W}$ and phylogenetic analysis were performed in MEGA version 4 (Tamura et al. 2007). Maximum parsimony analysis was performed for all datasets using the heuristic search option. The robustness of the most parsimonious trees was evaluated with 1000 bootstrap replications (Hillis and Bull 1993). Sequences of Saccharomyces cerevisiae S228C were used as outgroup in the analyses of all used loci. Newly generated sequences were deposited in GenBank with accession numbers HQ871703-HQ871841 (Table 1). The generated alignments and the most parsimonious trees were deposited in TreeBase under accession number 11154 (http://purl.org/ phylo/treebase/phylows/study/TB2:S11154).

The genotype of each isolate listed as M. thermophila was determined using AFLP fingerprint analysis, as described previously by Boekhout et al. (2001).

\section{Mating experiment}

The mating experiment was performed on two media: Malt Extract Agar (MEA) and Oatmeal Agar (OA) medium (Samson et al. 2010). A small agar plug containing mycelium (1 mm diameter) from the edge of a vigorously growing 1day-old colony on MEA medium was transferred to the Petri dishes with OA or MEA media. The initial combination of isolates CBS202.75 and CBS203.75 with one of the nine other $M$. thermophila isolates were incubated in the dark at $35^{\circ} \mathrm{C}$ (von Klopotek 1974). The combination of isolates CBS117.65, CBS173.70, CBS381.97, CBS669.85, CBS866.85 and ATCC42464 were incubated in the dark at $30^{\circ} \mathrm{C}, 35^{\circ} \mathrm{C}, 40^{\circ} \mathrm{C}$ or $45^{\circ} \mathrm{C}$. The mating experiment was conducted twice for each combination of isolates.

\section{Results}

Phylogeny of genera Corynascus and Myceliophthora

Forty-nine isolates of the genera Myceliophthora and Corynascus were phylogenetically investigated by compar- 
Table 1 Myceliophthora and Corynascus isolates examined in this study. Type isolates are indicated with ${ }^{\mathrm{T}}$

\begin{tabular}{|c|c|c|c|c|c|c|}
\hline $\begin{array}{l}\text { Original } \\
\text { species name }\end{array}$ & $\begin{array}{l}\text { Proposed } \\
\text { species name }\end{array}$ & Accession no. & $\begin{array}{l}\text { Source and } \\
\text { remarks }\end{array}$ & $\begin{array}{l}\text { GenBank } \\
\text { no. ITS1 }\end{array}$ & $\begin{array}{l}\text { GenBank } \\
\text { no. } E F 1 A\end{array}$ & $\begin{array}{l}\text { GenBank } \\
\text { no. } R P B 2\end{array}$ \\
\hline \multirow[t]{6}{*}{ M. thermophila } & \multirow[t]{6}{*}{ M. thermophila } & CBS $117.65^{\mathrm{T}}$ & Dry pasture soil, UK & HQ871764 & HQ871705 & HQ871803 \\
\hline & & CBS 173.70 & Wheat straw compost, UK & HQ871765 & HQ871706 & HQ871804 \\
\hline & & CBS 381.97 & $\begin{array}{l}\text { Man, HIV pos. patient, } \\
\text { unknown location }\end{array}$ & HQ871766 & HQ871707 & HQ871805 \\
\hline & & CBS 669.85 & $\begin{array}{l}\text { Unknown source; mutant of } \\
\text { CBS } 866.85\end{array}$ & HQ871767 & HQ871704 & HQ871806 \\
\hline & & CBS 866.85 & Unknown source & HQ871768 & HQ871708 & HQ871807 \\
\hline & & ATCC 42464 & Unknown source & HQ871769 & HQ871703 & HQ871802 \\
\hline \multirow[t]{5}{*}{ M. thermophila } & \multirow[t]{5}{*}{ M. heterothallica } & CBS 131.65 & Birch chips, Sweden & HQ871770 & HQ871709 & - \\
\hline & & CBS 202.75 & $\begin{array}{l}\text { Garden soil, Germany; authentic } \\
\text { strain of } T \text {. heterothallica }\end{array}$ & HQ871771 & HQ871710 & HQ871798 \\
\hline & & CBS 203.75 & $\begin{array}{l}\text { Soil, Indiana, USA; authentic } \\
\text { strain of T.heterothallica }\end{array}$ & HQ871772 & HQ871711 & HQ871800 \\
\hline & & CBS 375.69 & $\begin{array}{l}\text { Woodpulp, New Brunswick, } \\
\text { Canada }\end{array}$ & HQ871773 & HQ871712 & HQ871799 \\
\hline & & CBS 663.74 & $\begin{array}{l}\text { Soil under a baobab } \\
\text { (Adansonia digitata), Senegal }\end{array}$ & HQ871774 & HQ871713 & HQ871801 \\
\hline \multirow[t]{11}{*}{ M. lutea } & \multirow[t]{11}{*}{ M. lutea } & CBS $145.77^{\mathrm{T}}$ & Hay, UK & HQ871775 & HQ871722 & HQ871816 \\
\hline & & CBS 146.50 & Mushroom bed, Delaware, USA & HQ871776 & HQ871724 & HQ871818 \\
\hline & & CBS 146.77 & Barley (Hordeum vulgare), Ireland & HQ871777 & HQ871725 & HQ871819 \\
\hline & & CBS 147.50 & Mushroom bed, Pennsylvania, USA & HQ871778 & HQ871726 & HQ871820 \\
\hline & & CBS 147.77 & Dust in stable, UK & HQ871779 & HQ871728 & HQ871821 \\
\hline & & CBS 157.51 & Mushroom bed, Netherlands & HQ871780 & HQ871730 & HQ871817 \\
\hline & & CBS 157.59 & Air in pigsty, Netherlands & HQ871781 & HQ871729 & HQ871822 \\
\hline & & CBS 227.67 & Mushroom bed, Netherlands & HQ871782 & HQ871721 & HQ871823 \\
\hline & & CBS 243.75A & Air, Uttar Pradesh, India & HQ871783 & HQ871723 & HQ871824 \\
\hline & & CBS 243.75B & Air, Uttar Pradesh, India & HQ871784 & HQ871720 & HQ871826 \\
\hline & & CBS 379.76 & Usar soil, Uttar Pradesh, India & HQ871785 & HQ871727 & HQ871825 \\
\hline \multirow[t]{6}{*}{ M. hinnulea } & \multirow[t]{6}{*}{ M. hinnulea } & CBS 539.82 & $\begin{array}{l}\text { Soil from cultivated garden, } \\
\text { New Zealand }\end{array}$ & HQ871786 & HQ871714 & HQ871808 \\
\hline & & CBS 540.82 & $\begin{array}{l}\text { Soil under Monterey Pine } \\
\text { (Pinus radiata), New Zealand }\end{array}$ & HQ871787 & HQ871716 & HQ871809 \\
\hline & & CBS 541.82 & $\begin{array}{l}\text { Sun-exposed garden soil, } \\
\text { New Zealand }\end{array}$ & HQ871788 & HQ871715 & HQ871810 \\
\hline & & CBS 542.82 & $\begin{array}{l}\text { Sun-exposed garden soil, } \\
\text { New Zealand }\end{array}$ & HQ871789 & HQ871717 & HQ871811 \\
\hline & & CBS 544.82 & Soil, New Zealand & HQ871790 & HQ871718 & HQ871812 \\
\hline & & CBS $597.83^{\mathrm{T}}$ & Cultivated soil, Japan & HQ871791 & HQ871719 & HQ871813 \\
\hline \multirow[t]{3}{*}{ M. vellerea } & \multirow[t]{3}{*}{ Ctenomyces vellerea } & CBS 478.76 & Unknown source, Egypt & HQ871796 & HQ871748 & - \\
\hline & & CBS 479.76 & Unknown source, Egypt & HQ871797 & HQ871749 & HQ871840 \\
\hline & & CBS 715.84 & $\begin{array}{l}\text { Soil, Alberta, Canada; ex-type } \\
\text { of C. asperatum }\end{array}$ & HQ871795 & HQ871747 & HQ871841 \\
\hline \multirow[t]{3}{*}{ C. thermophilus } & \multirow[t]{3}{*}{ M. fergusii } & CBS 174.70 & Wheat straw compost, UK & HQ871792 & - & - \\
\hline & & CBS 405.69 & $\begin{array}{l}\text { Mushroom compost, Pennsylvania, } \\
\text { USA; MT + }\end{array}$ & HQ871793 & HQ871731 & HQ871814 \\
\hline & & CBS $406.69^{\mathrm{T}}$ & $\begin{array}{l}\text { Mushroom compost, Pennsylvania, } \\
\text { USA; MT - }\end{array}$ & HQ871794 & HQ871732 & HQ871815 \\
\hline \multirow[t]{6}{*}{ C. sepedonium } & \multirow[t]{6}{*}{ M. sepedonium } & CBS $111.69^{\mathrm{T}}$ & $\begin{array}{l}\text { Soil, Uttar Pradesh, India; ex-type } \\
\text { of T. sepedonium }\end{array}$ & HQ871751 & HQ871734 & HQ871827 \\
\hline & & CBS 213.74 & Sandy soil, Senegal & HQ871752 & HQ871736 & HQ871828 \\
\hline & & CBS 223.81 & Desert soil, Kuwait & HQ871753 & HQ871737 & HQ871831 \\
\hline & & CBS 294.56 & Buried cable in soil, Netherlands & HQ871754 & HQ871738 & HQ871832 \\
\hline & & CBS 340.33 & Unknown source & HQ871755 & HQ871739 & HQ871829 \\
\hline & & CBS 412.52 & Soil, Argentina & - & HQ871740 & HQ871833 \\
\hline
\end{tabular}


Table 1 (continued)

\begin{tabular}{|c|c|c|c|c|c|c|}
\hline $\begin{array}{l}\text { Original } \\
\text { species name }\end{array}$ & $\begin{array}{l}\text { Proposed } \\
\text { species name }\end{array}$ & Accession no. & $\begin{array}{l}\text { Source and } \\
\text { remarks }\end{array}$ & $\begin{array}{l}\text { GenBank } \\
\text { no. ITS1 }\end{array}$ & $\begin{array}{l}\text { GenBank } \\
\text { no. } E F 1 A\end{array}$ & $\begin{array}{l}\text { GenBank } \\
\text { no. } R P B 2\end{array}$ \\
\hline & & CBS 415.48 & Cotton rope, Uttar Pradesh, India & HQ871756 & HQ871741 & HQ871834 \\
\hline & & CBS 434.96 & Soil, Delhi, India & HQ871760 & - & - \\
\hline & & CBS 435.96 & Soil, Singapore & HQ871761 & HQ871745 & - \\
\hline & & CBS 438.96 & Soil, Uttar Pradesh, India & HQ871757 & HQ871742 & HQ871835 \\
\hline & & CBS 440.51 & Soil, UK & HQ871758 & HQ871743 & HQ871836 \\
\hline & & CBS 632.67 & $\begin{array}{l}\text { Unknown source, Russia; ex-type } \\
\text { of Thielavia lutescens }\end{array}$ & HQ871759 & HQ871744 & HQ871830 \\
\hline & & CBS 114383 & Barley (Hordeum vulgare), Iran & HQ871750 & HQ871735 & HQ871837 \\
\hline C. novoguineensis & M. novoguineensis & CBS 359.72 & Soil, Papua New Guinea & HQ871762 & HQ871733 & HQ871838 \\
\hline \multicolumn{2}{|c|}{ Corynascella inaequalis } & CBS 284.82 & Soil, Tarragona, Spain & HQ871763 & HQ871746 & HQ871839 \\
\hline
\end{tabular}

ison of sequences (Table 1) of five genomic loci, namely the internal transcribed spacer 1 (ITS1), part of elongation factor EF1A, part of the RNA polymerase subunit $R B P 2$, the D1/D2 locus of large ribosomal subunit and part of $B-$ tubulin $(T U B B)$. Unfortunately, the sequences of the D1/D2 locus did not have enough variation to perform a phylogenetic analysis. In addition, part of the $\beta$-tubulin locus of $M$. lutea was duplicated on the genome resulting in unclear sequences. Therefore, these two loci were eliminated from the comparison. The constructed phylogenetic trees of the remaining three loci were the results of a bootstrap consensus by maximum parsimony.

The phylogenies obtained from the three loci, ITS1, EF1A and $R B P 2$, gave a clear clustering of the isolates of each species (Figs. 1, 2 and 3). Except for M. vellerea, the isolates of Corynascus and Myceliophthora clustered together and showed a close relation to other isolates of the family Chaetomiaceae (e.g. Chaetomium globosum, Corynascella inaequalis and Thielavia terrestris). Based on the large differences of the ITS1, EF1A and RPB2 sequences of $M$. vellerea when compared to those of the Corynascus and other Myceliophthora species, it is clear that M. vellerea has been wrongly placed within the genus Myceliophthora. The ITS1 region of $M$. vellerea was highly similar to Ctenomyces serratus (661 of 678 nucleotides identical), suggesting that this species should be placed in the genus Ctenomyces.

The $C$. sepedonium isolates and related Corynascus species clustered together in all phylogenies. Only 1 of 456 nucleotides of the ITS1 sequences within this Corynascus cluster was found to be parsimony informative. The phylogenies of all three loci showed that $M$. lutea was the closest related species to $C$. sepedonium and related Corynascus species. Their close relation was represented by the ITS1 sequences of $C$. sepedonium and M. lutea, where only three nucleotides were parsimony informative.

The isolates of the thermophilic species M. hinnulea and M. thermophila were closely related in all phylogenies. The
ITS1 sequences of M. hinnulea and M. thermophila had 12 of 456 parsimony informative nucleotides. Both species clustered with the thermophilic species $C$. thermophilus in the trees of ITS1 and RPB2. Thirty-two of 456 nucleotides of the ITS1 sequences within this cluster of the three thermophilic fungi were found to be parsimony informative. However, in the EF1A tree, $C$. thermophilus clustered separately from all other Corynascus and Myceliophthora isolates.

Genetic diversity within the thermophilic Myceliophthora thermophila

The 11 isolates listed as $M$. thermophila consistently clustered in two groups at all phylogenies (Figs. 1, 2 and 3). This variation between the isolates is also reflected by the relatively high amount of informative sites at the three loci (e.g. 12 informative sites of 456 nucleotides of the ITS1 loci; $2.6 \%$ ). In comparison, this variation was similar to the sequence variation between the species $M$. hinnulea and $M$. thermophila. The group of 11 isolates of $M$. thermophila clustered into two main groups with the exception of $M$. thermophila CBS663.74. This latter isolate was placed between the two groups of $M$. thermophila in the ITS1 and EF1A trees, but grouped with CBS131.65, CBS202.75, CBS203.75 and CBS375.69 in the RPB2 tree.

The genetic variation within $M$. thermophila was further investigated by Amplified Fragment Length Polymorphism (AFLP). The banding patterns of the $11 M$. thermophila isolates confirmed the clustering in two groups (Fig. 4). The sequence data and AFLP analysis placed CBS117.65, CBS173.70, CBS381.97, CBS669.85, CBS866.85 and ATCC42464 in one group, while CBS131.65, CBS202.75, CBS203.75 and CBS375.69 were placed in a second group. The AFLP banding pattern of CBS663.74 did not fit with either of the groups, thus confirming the results of the phylogenies of ITS1 and EF1A (Figs. 1 and 2) in which CBS663.74 occurred outside both groups of M. thermophila. 
Fig. 1 Parsimonious consensus tree of the analysed ITS1 region of Myceliophthora sp. and Corynascus sp. (134 of the 389 nucleotides were parsimony informative). The percentage of replicate trees, in which the associated taxa clustered together in the bootstrap test (1000 replicates), are shown next to the branches. All positions containing gaps and missing data were eliminated from the dataset
Corynascus sepedonium CBS111.69

Corynascus similis (AJ224203)

Corynascus sepedonium CBS438.96

Corynascus sepedonium CBS434.96

Corynascus sepedonium CBS415.48

Corynascus verrucosus (FJ537093)

Corynascus sepedonium CBS440.51

Corynascus verrucosus (AJ224203)

66 Corynascus sepedonium CBS114383

- Corynascus sepedonium (AJ439447)

Corynascus sepedonium CBS340.33

Corynascus sepedonium CBS435.96

Corynascus sepedonium CBS223.81

Corynascus sepedonium CBS294.56

Corynascus sepedonium CBS213.74

- Corynascus similis (AJ224201)

Corynascus sepedonium CBS632.67

Corynascus novoguineensis CBS359.72

- Corynascus sexualis (AJ224202)

Myceliophthora lutea CBS145.77

Myceliophthora lutea CBS243.75B

Myceliophthora lutea CBS379.76

Myceliophthora lutea CBS146.50

Myceliophthora lutea CBS157.51

Myceliophthora lutea CBS147.77

Myceliophthora lutea CBS157.59

Myceliophthora lutea CBS146.77

Myceliophthora lutea CBS147.50

- Myceliophthora lutea CBS227.67

Myc

(1)

Myceliophthora hinnulea CBS542 82

25 Myceliophthora hinnulea CBS540.82

Myceliophthora hinnulea CBS541.97

${ }_{27}$ Myceliophthora hinnulea CBS544.82

- Myceliophthora hinnulea CBS597.83

Corynascus thermophilus CBS405.69

Corynascus thermophilus CBS174.70

99 Corynascus thermophilus CBS406.69 Myceliophthora thermophila CBS131.65

67 Myceliophthora thermophila CBS375.69

Myceliophthora thermophila CBS202.75

Myceliophthora thermophila CBS203.75

Myceliophthora thermophila CBS663.74

63 Myceliophthora thermophila CBS669.85

Myceliophthora thermophila CBS866.85

92 Myceliophthora thermophila CBS173.70

Myceliophthora thermophila (HM149535)

66 Myceliophthora thermophila ATCC42464

Myceliophthora thermophila CBS117.65

Myceliophthora thermophila CBS381.97

Corynascella inaequalis CBS284.82

44 _ Chaetomium globosum CBS148.51

Thielavia terrestris NRRL8126

99 Arthroderma tuberculatum (AJ877221)

Arthroderma tuberculatum (AJ390383)

Ctenomyces serratus (AJ877222)

Myceliophthora vellerea CBS715.84

99

Myceliophthora vellerea CBS478.76

Myceliophthora vellerea CBS479.76

Saccharomyces cerevisiae S288c outgroup 
Fig. 2 Parsimonious consensus tree of the analysed elongation factor $E F 1 A$ gene sequences of Myceliophthora sp. and Corynascus sp. (136 of the 654 nucleotides were parsimony informative). The percentage of replicate trees, in which the associated taxa clustered together in the bootstrap test (1000 replicates), are shown next to the branches. All positions containing gaps and missing data were eliminated from the dataset

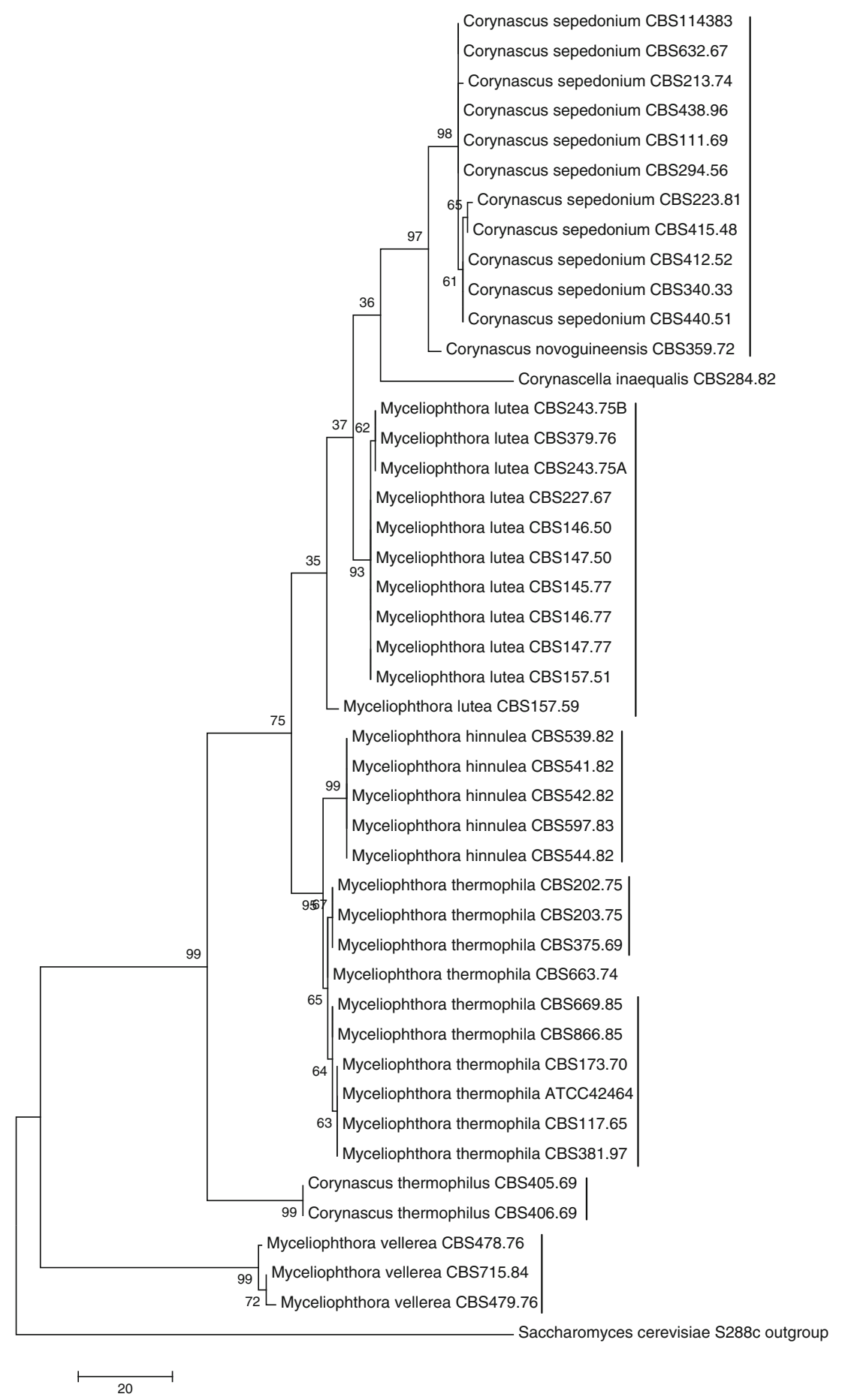

Mating types of Myceliophthora thermophila isolates

The mating behavior of each $M$. thermophila isolate was studied by crossing the two mating types CBS202.75 and CBS203.75 with each of the nine other $M$. thermophila isolates. After 3 weeks, all plates had ascomata containing dark brown ascospores at the contact zone between CBS202.75 and CBS203.75 (Fig. 5e-g). The dark colored ascomata were produced in the agar media and were only visible at the reverse of plates (Fig. 5a-d). The mating experiment showed that CBS202.75 and CBS663.74 had the same mating type, while CBS203.75, CBS131.65, and CBS375.69 had the opposite mating type (Table 2). These isolates all belong to one of the $M$. thermophila groups based on the phylogenies described above. The remaining six $M$. thermophila isolates, belonged to the 
Fig. 3 Parsimonious consensus tree of the analysed partial $R P B 2$ gene sequences of Myceliophthora sp. and Corynascus sp. ( 257 of the 611 nucleotides were parsimony informative). The percentage of replicate trees, in which the associated taxa clustered together in the bootstrap test (1000 replicates), are shown next to the branches. All positions containing gaps and missing data were eliminated from the dataset

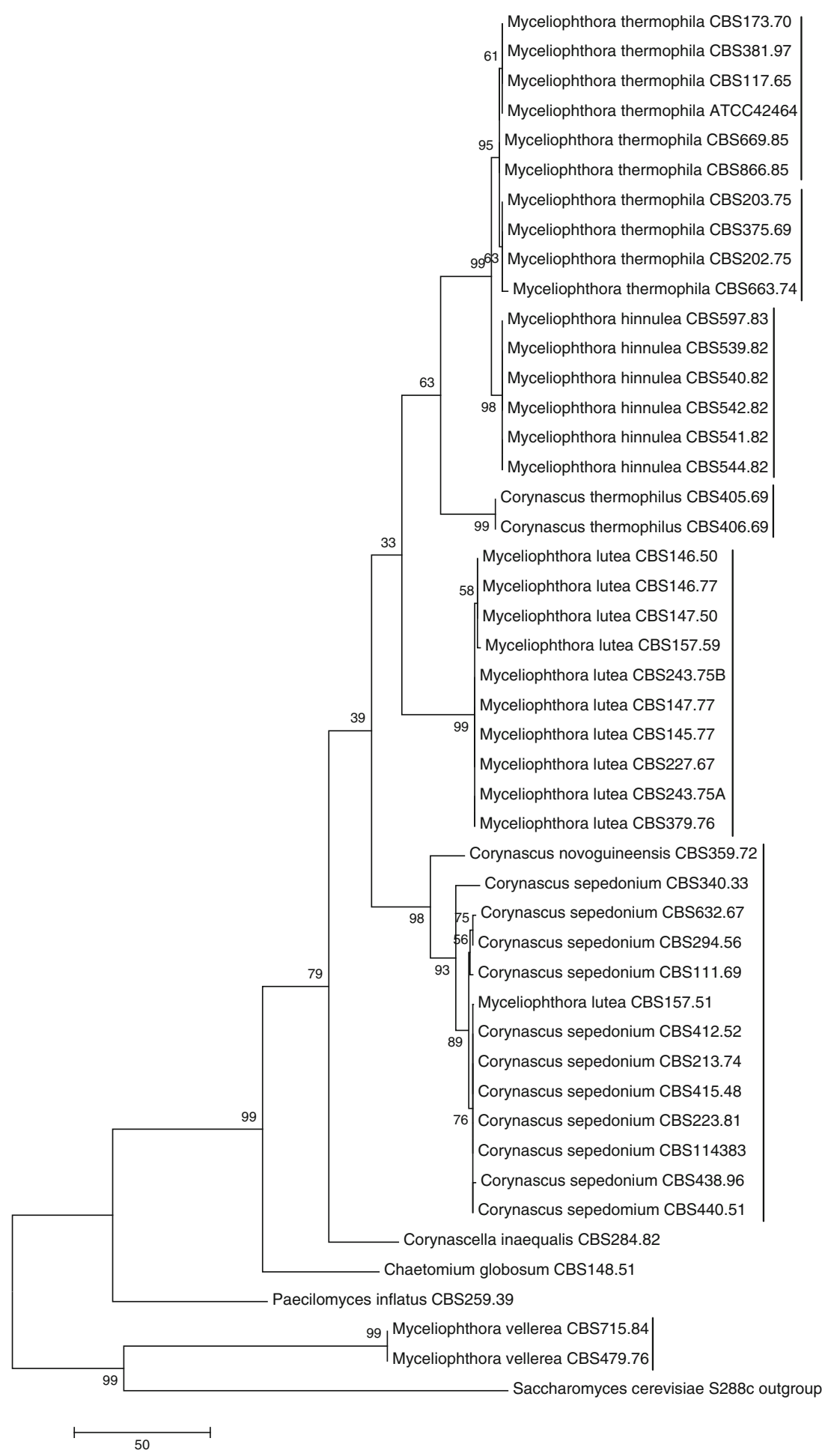

other phylogenetic group, and did not produce fruiting bodies at the contact zone with CBS202.75 or CBS203.75. Moreover, when combined with each other on oatmeal agar plates, isolates CBS117.65, CBS173.70, CBS381.97, CBS669.85, CBS866.85 and ATCC42464 were not able to produce fruiting bodies after 4 weeks at $30^{\circ} \mathrm{C}, 35^{\circ} \mathrm{C}, 40^{\circ} \mathrm{C}$ or $45^{\circ} \mathrm{C}$.

\section{Discussion}

Myceliophthora: a single name for species hitherto classified in Corynascus and Myceliophthora

The molecular phylogeny of Myceliophthora and Corynascus gave new insights into the taxonomic relationships between 
$\%$ similarity

$\begin{array}{lllll}20 & 40 & 60 & 80 & 100\end{array}$

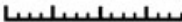

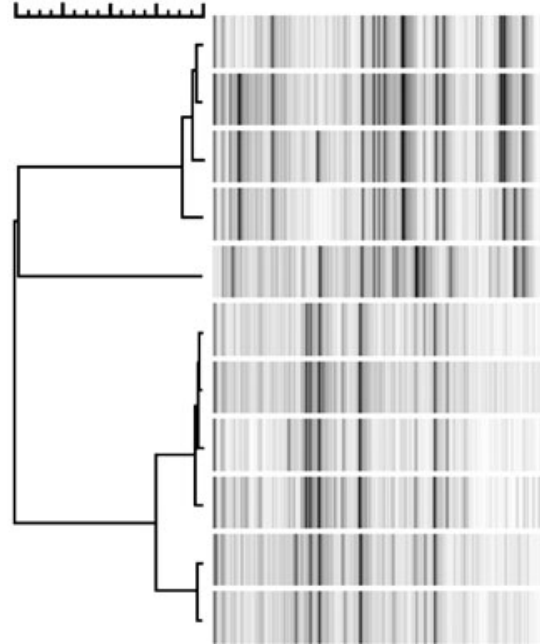

AFLP banding patterns

strain no.

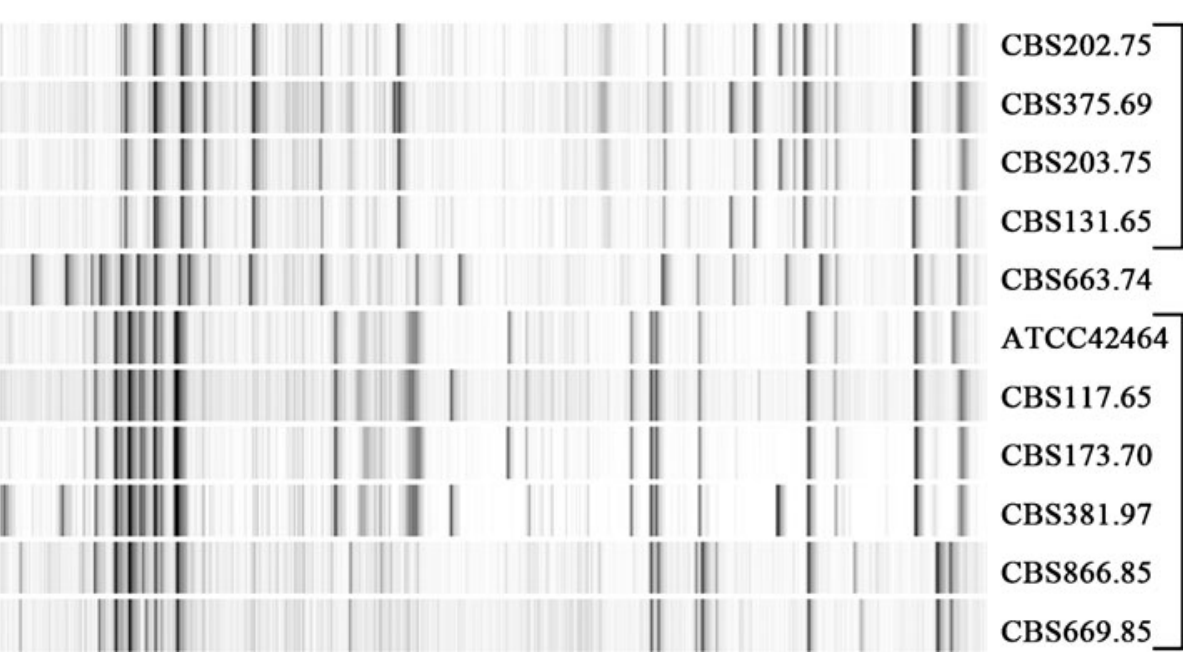

Fig. 4 Clustering of AFLP banding patterns of Myceliophthora thermophila isolates. Similarity of the banding patterns is given in percentage

Reverse
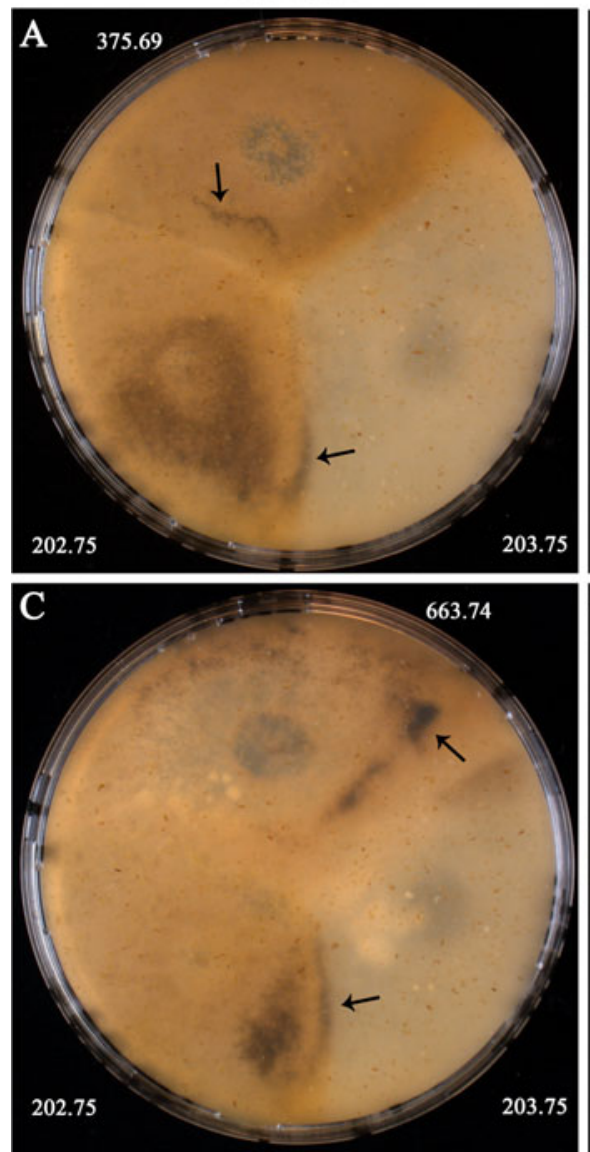

Obverse

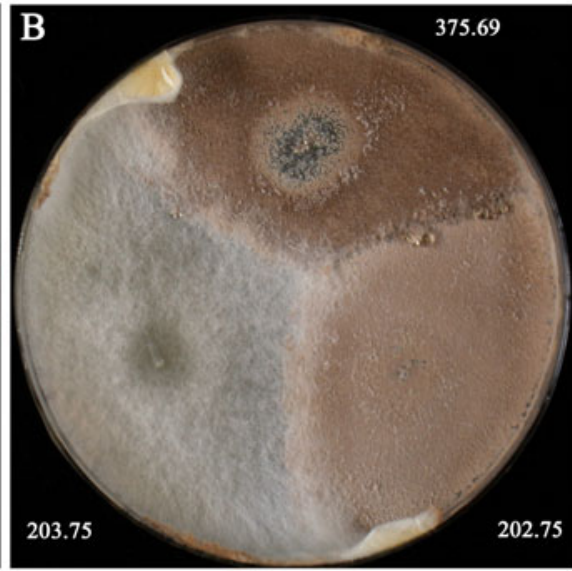

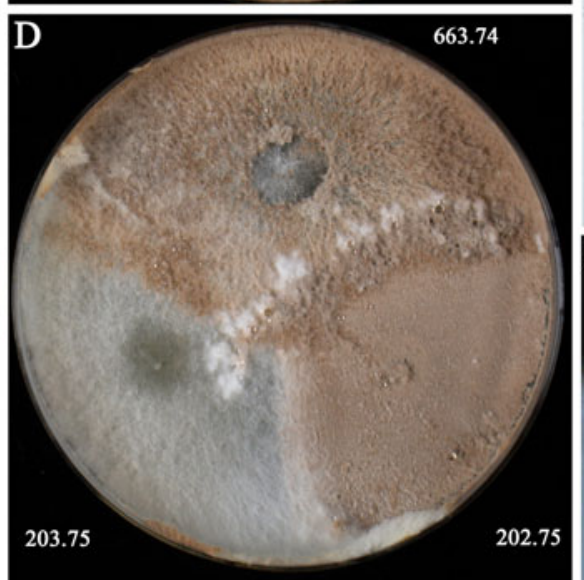
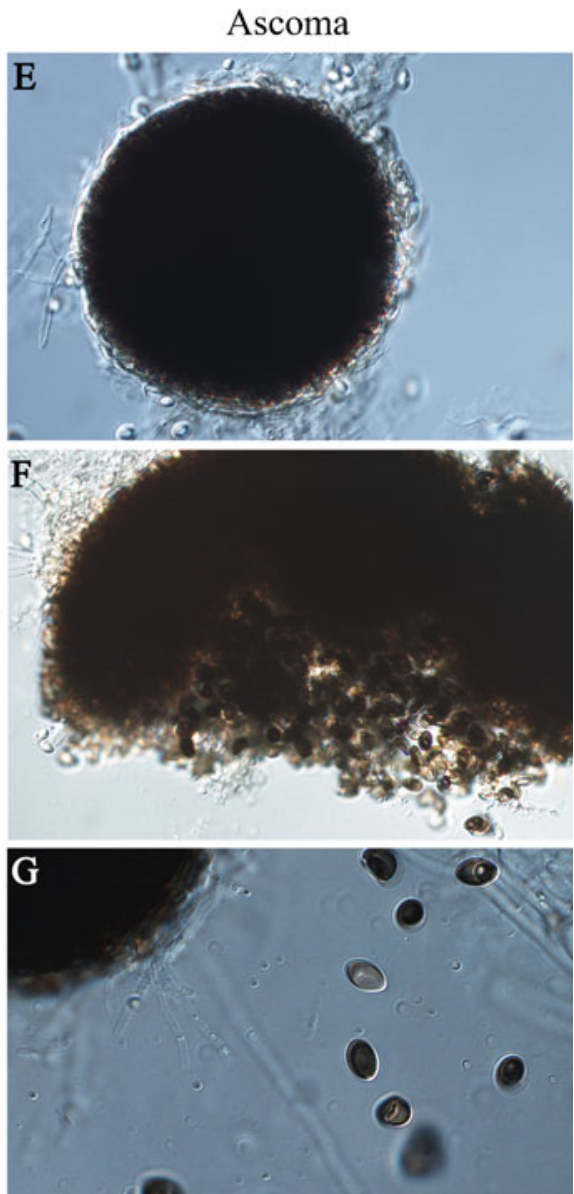

Fig. 5 Plates with different Myceliophthora thermophila isolates and microscope pictures of the formed ascoma. Figure $\mathbf{a}$ and $\mathbf{b}$ are, respectively, the reverse and obverse of a plate depicting the mating between $M$. thermophila CBS375.69 \& CBS202.75 and CBS202.75 $\&$ CBS203.75. Figure $\mathbf{c}$ and $\mathbf{d}$ are, respectively, the reverse and obverse of a plate depicting the mating between $M$. thermophila CBS663.74 \& CBS203.75, and CBS202.75 \& CBS203.75. Formed ascoma in figure $\mathbf{a}$ and $\mathbf{c}$ are indicated with an arrow. Figure $\mathbf{e}, \mathbf{f}$ and $\mathbf{g}$ are microscope pictures of the produced ascoma and ascospores, respectively, $\times 100, \times 400$ and $\times 1000$ 
Table 2 Mating types of Myceliophthora thermophila

\begin{tabular}{ll}
\hline Accession no. & Mating type $(+,-$, absent $)$ \\
\hline CBS202.75 & MT + \\
CBS663.74 & MT + \\
CBS131.65 & MT - \\
CBS203.75 & MT - \\
CBS375.69 & MT - \\
CBS117.65 & absent \\
CBS173.70 & absent \\
CBS381.97 & absent \\
CBS669.85 & absent \\
CBS866.85 & absent \\
ATCC42464 & absent \\
\hline
\end{tabular}

these two genera. Firstly, the ITS1 sequences of CBS478.76, CBS479.76 and CBS715.84 confirmed that $M$. vellerea does not belong to Myceliophthora and should be classified as Ctenomyces serratus. This was already suggested based on morphological characteristics (Guarro et al. 1985).

Another observation was the sequence similarity of many Corynascus species. Although morphological differences have been observed, the ITS1 sequence of $C$. sepedonium, C. sexualis, $C$. similis, C. novoguineensis and $C$. verrucosus were more than $99.5 \%$ similar. This contrast between morphology and ITS1 phylogeny for Corynascus species has already been reported before (Stchigel et al. 2000). The EF1A and $R P B 2$ sequences of $C$. sepedonium and $C$. novoguineensis showed more diversity and might justify the current classification within Corynascus. This shows that analysis of multiple loci (Samson et al. 2007) is useful, especially in the phylogenetic characterization of Corynascus species.

The isolates of $C$. sepedonium and $M$. lutea are closely related based on all generated phylogenies. Another common feature of $C$. sepedonium and $M$. lutea is their optimal growth temperature. The isolates of these species prefer to grow below $40^{\circ} \mathrm{C}$, while the thermophilic Corynascus and Myceliophthora species have an optimal growth around $45^{\circ} \mathrm{C}$ (tested on malt extract agar plates, Supplemental data 1). These results show that fungi within the genera Corynascus and Myceliophthora can be split into two clusters: i.e., a mesophilic and a thermophilic cluster.

A clear separation of the two genera Corynascus and Myceliophthora is, however, not apparent from the phylogenetic data. Some species of the genus Corynascus have been the associated teleomorph of the anamorphic species classified within Myceliophthora (van Oorschot 1980). However, most species have unknown teleomorphs or anamorphs and the phylogenetic data in our study did not clarify this issue. CBS440.51 for instance has been described as an anamorph of $C$. sepedonium (van Oorschot 1980). No differences were observed in the sequence data between the anamorphs and teleomorphs of $C$. sepedonium.
The dual name for this single taxon of species belonging to Myceliophthora and Corynascus should be used carefully. The issue of a single scientific name for fungal species has been increasingly raised, especially since genetic studies have become common practice (Rossman and Samuels 2005; Shenoy et al. 2007; Samson and Varga 2009; Hawksworth 2011). Given that the genus name Myceliophthora was described in 1894 and Myceliophthora is a common name in publications, we propose to name all Corynascus species as Myceliophthora. This forms no obstacle for most species of Corynascus as their species name is unique for the genus Myceliophthora. Only Corynascus thermophilus should be renamed under its old anamorph name M. fergusii (van Oorschot 1977). For $C$. thermophilus, C. novoguineensis, C. sepedonium, C. sexualis, $C$. similis, and $C$. verrucosus the formal new combinations are listed at the end of the manuscript.

Genetic diversity and mating behavior set $M$. heterothallica apart from $M$. thermophila

The collection of the CBS-KNAW Fungal Biodiversity Centre contains ten isolates listed as $M$. thermophila (basionym: Sporotrichum thermophilum). The phylogenetic data revealed clear differences between the isolates and divided these isolates in two groups. One group contained the type isolate of $M$. thermophila and the strain ATCC42464, whose full genomic sequence is available. The other group consisted of five isolates including strains CBS202.75 and CBS203.75, which are authentic isolates of Thielavia heterothallica (von Klopotek 1976). Isolates of this later group can mate with each other and their mating types were identified. In light of the phylogenetic and biological species concept, we suggest that this teleomorph group will be named Myceliophthora heterothallica. For Thielavia heterothallica the formal new combination to the Myceliophthora is listed at the end of the manuscript.

According to the sequence data and AFLP analysis, CBS663.74 was different from the other isolates belonging to the $M$. thermophila and $M$. heterothallica group at the genetic level. This strain was also the only one obtained from the African continent, where it was isolated from soil under a baobab tree in Senegal. Nevertheless, the genetic differences did not prevent mating of CBS663.74 with other $M$. heterothallica isolates, suggesting that this isolate fits within the $M$. heterothallica group.

Fungi of the genus Myceliophthora, especially $M$. thermophila, are of industrial interest due to their potential to produce thermophilic enzymes (Bhat and Maheshwari 1987; Roy et al. 1990; Sadhukhan et al. 1992; Badhan et al. 2007; Beeson et al. 2011). This study described the genetic diversity amongst different Myceliophthora isolates and divided $M$. thermophila isolates in two species $M$. thermo- 
phila and M. heterothallica. From the applied point of view, it will be of interest to investigate the physiological differences between both thermophilic fungi.

Myceliophthora Costantin 1892, in Cr Hebd Séanc Acad Sci Paris 114; 849-851

Myceliophthora lutea Costantin 1892 (MB232833)Type species

- Synonym: Scopulariopsis lutea (Costantin) Tubaki 1955 (MB305672)

- Synonym: Chrysosporium luteum (Costantin) J.W. Carmich. 1962 (MB328210)

- Synonym: Sporotrichum carthusioviride J.N. Rai \& Mukerji 1962 (MB339566)

Myceliophthora hinnulea Awao and Udagawa 1983 (MB109090)

Myceliophthora thermophila (Apinis) Oorschot 1977 (MB317955)

- Basionym: Sporotrichum thermophilum Apinis 1963 (MB344529)

- Synonym: Chrysosporium thermophilum (Apinis) Klopotek 1974 (MB311112)

Myceliophthora heterothallica (von Klopotek) van den Brink \& Samson, comb. nov. (MB 519538)

- Basionym: Thielavia heterothallica von Klopotek 1976 (MB324556)

- Synonym: Corynascus heterothallicus (von Klopotek) von Arx, Dreyfuss \& Müller 1984 (MB107879)

Myceliophthora fergusii (Klopotek) van Oorschot 1977 (MB317954)

- Synonym: Thielavia thermophila Fergus and Sinden 1969 (MB340061)

- Synonym: Corynascus thermophilus (Fergus \& Sinden) Klopotek 1974 (MB312215)

- Synonym: Chaetomidium thermophilum (Fergus \& Sinden) Lodha 1978 (MB310883)

Myceliophthora sepedonium (C.W. Emmons) van den Brink \& Samson, comb. nov. (MB561525)

- Basionym: Thielavia sepedonium C.W. Emmons 1932 (MB277883)

- Synonym: Corynascus sepedonium (C.W. Emmons) von Arx 1973 (MB312213)

- Synonym: Chaetomidium sepedonium (C.W. Emmons) Lodha 1978 (MB310880)

- Synonym: Thielavia sepedonium var. minor Mehrotra \& Bhattacharjee 1966 (MB353893)
Myceliophthora novoguineensis (Udagawa \& Y. Horie) van den Brink \& Samson, comb. nov. (MB561526)

- Basionym: Corynascus novoguineensis (Udagawa \& Y. Horie) von Arx 1973 (MB312212)

Myceliophthora sexualis (Stchigel, Cano \& Guarro) van den Brink \& Samson, comb. nov. (MB561527)

- Basionym: Corynascus sexualis Stchigel, Cano \& Guarro 2000 (MB467480)

Myceliophthora similis (Stchigel, Cano \& Guarro) van den Brink \& Samson, comb. nov. (MB561528)

- Basionym: Corynascus similis Stchigel, Cano \& Guarro 2000 (MB467481)

Myceliophthora verrucosa (Stchigel, Cano \& Guarro) van den Brink \& Samson, comb. nov. (MB561529)

- Basionym: Corynascus verrucosus Stchigel, Cano \& Guarro 2000 (MB467482)

Acknowledgements This work has been supported by the EC $7^{\text {th }}$ Framework program (NEMO, Project Grant agreement 222699).

Open Access This article is distributed under the terms of the Creative Commons Attribution Noncommercial License which permits any noncommercial use, distribution, and reproduction in any medium, provided the original author(s) and source are credited.

\section{References}

Awao T, Udagawa SI (1983) A new thermophilic species of Myceliophthora. Mycotaxon 16:436-441

Babot ED, Rico A, Rencoret J, Kalum L, Lund H, Romero J, Del Río JC, Martínez AT, Gutiérrez A (2011) Towards industriallyfeasible delignification and pitch removal by treating paper pulp with Myceliophthora thermophila laccase and a phenolic mediator. Bioresour Technol. doi:10.1016/j.biortech.2011.03.100 [Epub ahead of print]

Badhan AK, Chadha BS, Kaur J, Saini HS, Bhat MK (2007) Production of multiple xylanolytic and cellulolytic enzymes by thermophilic fungus Myceliophthora sp. IMI 387099. Bioresour Technol 98:504-510

Beeson WT 4th, Iavarone AT, Hausmann CD, Cate JH, Marletta MA (2011) Extracellular aldonolactonase from Myceliophthora thermophila. Appl Environ Microbiol. doi:10.1128/AEM.01922-10 [Epub ahead of print]

Berka RM, Schneider P, Golightly EJ, Brown SH, Madden M, Brown KM, Halkier T, Mondorf K, Xu F (1997) Characterization of the gene encoding an extracellular laccase of Myceliophthora thermophila and analysis of the recombinant enzyme expressed in Aspergillus oryzae. Appl Environ Microbiol 63:3151-3157

Bhat KM, Maheshwari R (1987) Sporotrichum thermophile Growth, Cellulose Degradation, and Cellulase Activity. Appl Environ Microbiol 53:2175-2182

Boekhout T, Theelen B, Diaz M, Fell JW, Hop WC, Abeln EC, Dromer F, Meyer W (2001) Hybrid genotypes in the pathogenic yeast Cryptococcus neoformans. Microbiology 147:891-907 
Bulter T, Alcalde M, Sieber V, Meinhold P, Schlachtbauer C, Arnold FH (2003) Functional expression of a fungal laccase in Saccharomyces cerevisiae by directed evolution. Appl Environ Microbiol 69:987-995

Carmichael JW (1962) Chrysosporium and some other aleurosporic hyphomycetes. Canadian Journal of Botany 40:1137-1175

Costantin J (1892) Sur quelques maladies du blanc de champignons. Cr Hebd Séanc Acad Sci Paris 114:849-851

Emmons CW (1932) The development of the ascocarp in two species of Thielavia. Bull Torrey Bot Club 59:415-422

Fergus CL, Sinden JW (1969) A new thermophilic fungus from mushroom compost: Thielavia thermophila spec. nov. Canadian Journal of Botany 47:1635-1637

Guarro J, Punsola L, Cano J (1985) Myceliophthora vellerea (Chrysosporium asperatum) anamorph of Ctenomyces serratus. Mycotaxon 23:419-427

Hawksworth DL (2011) Naming Aspergillus species: progress towards one name for each species. Med Mycol 49 (Suppl 1): S70-76

Hillis DM, Bull JJ (1993) An empirical test of bootstrapping as a method for assessing confidence in phylogenetic analysis. Systematic Biology 42:182-192

Houbraken J, Due M, Varga J, Meijer M, Frisvad JC, Samson RA (2007) Polyphasic taxonomy of Aspergillus section Usti. Stud Mycol 59:107-128

Rosgaard L, Pedersen S, Cherry JR, Harris P, Meyer AS (2006) Efficiency of new fungal cellulase systems in boosting enzymatic degradation of barley straw lignocellulose. Biotechnol Prog 22:493-498

Rossman AY, Samuels GJ (2005) Towards a single scientific name for species of fungi. Inoculum 56:3-6

Roy SK, Dey SK, Raha SK, Chakrabarty SL (1990) Purification and properties of an extracellular endoglucanase from Myceliophthora thermophila D-14 (ATCC 48104). J Gen Microbiol 136:1967-1971

Sadhukhan R, Roy SK, Raha SK, Manna S, Chakrabarty SL (1992) Induction and regulation of alpha-amylase synthesis in a cellulolytic thermophilic fungus Myceliophthora thermophila D14 (ATCC 48104). Indian J Exp Biol 30:482-486
Samson RA, Varga J (2009) What is a species in Aspergillus? Med Mycol 47(Suppl 1):S13-S20

Samson RA, Varga J, Witiak SM, Geiser DM (2007) The species concept in Aspergillus: recommendations of an international panel. Stud Mycol 59:71-73

Samson RA, Houbraken J, Thrane U, Frisvad JC, Andersen B (2010) Food and Indoor Fungi. CBS Fungal Biodiversity Centre, Utrecht, Netherlands

Shenoy BD, Jeewon R, Hyde KD (2007) Impact of DNA sequencedata on the taxonomy of anamorphic fungi. Fungal Diversity 26:1-54

Sigler L, Aneja KR, Kumar R, Maheshwari R, Shukla RV (1998) New records from India and redescription of Corynascus thermophilus and its anamorph Myceliophthora thermophila. Mycotaxon 68:185-192

Stchigel AM, Sagues M, Cano J, Guarro J (2000) Three new thermotolerant species of Corynascus from soil, with a key to the known species. Mycol Res 104:879-887

Tamura K, Dudley J, Nei M, Kumar S (2007) MEGA4: Molecular Evolutionary Genetics Analysis (MEGA) software version 4.0. Mol Biol Evol 24:1596-1599

van Oorschot CAN (1977) The genus Myceliophthora. Persoonia 9:404-409

van Oorschot CAN (1980) A revision of Chrysosporium and allied genera. Stud Mycol 20:1-89

von Arx JA (1973) Further observations on Sporotrichum and some similar fungi. Persoonia 7:127-131

von Arx JA, Dreyfuss M, Müller E (1984) A revaluation of Chaetomium and the Chaetomiaceae. Persoonia 12:169-179

von Klopotek A (1974) Revision of thermophilic Sporotrichum species: Chrysosporium thermophilum (Apinis) comb. nov. and Chrysosporium fergusii spec. nov. equal status conidialis of Corynascus thermophilus Fergus and (Sinden) comb. nov. Arch Microbiol 98:365-369

von Klopotek A (1976) Thielavia heterothallica spec. nov., die perfekte Form von Chrysosporium thermophilum. Arch Microbiol 107:223 